\title{
ANALISIS FORECASTING PADA JUMLAH KASUS GIZI BURUK DI PROVINSI SULAWESI TENGGARA TAHUN 2019 - 2023
}

\author{
Fitri Rachmillah Fadmi ${ }^{1}$ Sri Mulyani ${ }^{2}$ \\ 1,2Program Studi Kesehatan Masyarakat, STIKES Mandala Waluya, Kendari \\ fitri.rachmillahfadmi@gmail.com ${ }^{1}$ mulyani0870@gmail.com ${ }^{2}$
}

\begin{abstract}
Abstrak
Salah satu kriteria dalam penanganan masalah gizi bahwa satu kasus gizi buruk di suatu daerah sudah dapat dikategorikan ke dalam Kejadian Luar Biasa (KLB) gizi buruk. Mengacu pada kriteria ini, maka pada tahun 2017 di seluruh wilayah Sulawesi Tenggara telah mengalami KLB gizi. Untuk itu perlu dilakukan upaya pencegahan dini dengan analisis peramalan (forecasting) data berkala (time series).Penelitian ini bertujuan untuk mengetahui analisis forecasting menggunakan metode time series pada data kasus gizi buruk di Provinsi Sulawesi Tenggara. Jenis penelitian ini adalah kuantitatif deskriptif dengan pendekatan Analisis Data Sekunder (ADS) yang dianalisis dengan analisis rangkaian berkala (time series). Populasi yang digunakan dalam penelitian ini adalah seluruh data time series gizi buruk berdasarkan jenis kelamin dan wilayah kabupaten/kota selama periode 2013 - 2017 di Provinsi Sulawesi Tenggara sebanyak 1.327 data. Analisis data penelitian ini menggunakan analisis forecasting dengan metode time series pendekatan trend (trend linier, trend quadratic dan trend exponensial). Prediksi jumlah kasus gizi buruk di Provinsi Sulawesi Tenggara periode tahun 2013 - 2017 menggunakan pendekatan trend quadratic. Hasil prediksi tahun 2019 - 2023 menunjukkan bahwa peningkatan kasus akan terjadi pada wilayah Kabupaten Muna, Bombana, Wakatobi, Konawe Utara, Kolaka Timur, Muna Barat, Buton Selatan dan Kota Bau-Bau. Peningkatan kasus tertinggi terjadi di Kabupaten Wakatobi dengan pucak peningkatan diprediksi akan terjadi pada tahun 2023. Analisis trend model terbaik untuk prediksi jumlah kasus gizi buruk di Provinsi Sulawesi Tenggara tahun 2019- 2023 adalah quadratic.
\end{abstract}

Kata Kunci: giziburuk; forecasting; timeseries

\begin{abstract}
One of the criteria in the nutritional problem is that a malnutrition problem in an area can be categorized into Extraordinary Occurrence (KLB) of Malnutrition. Referring to this criterion, in 2017 all Southeast Sulawesi regions have increased nutritional outbreaks. For this reason, a preliminary experiment with periodic (Forecasting) data analysis (time series) is required.The study aimed to determineforecasting analysis using time series data on cases of malnutrition in Southeast Sulawesi Province.This type of research is quantitative descriptive using Secondary Data Analysis (ADS) which is analyzed by time series analysis. The population used in this study was all data series of malnutrition time based on gender and regency/city area during the period 2013 - 2017 in Southeast Sulawesi Province as many as 1,327 data. Data analysis in this study uses forecasting analysis with the time series method of studying trends (linear trends, quadratic trends and exponential trends). Prediction of the amount of malnutrition in Southeast Sulawesi Province in the period 2013-2017 uses quadratic trends. Prediction results for 2019-2023 showed that the predicted increase that will occur in North Konawe, Wakatobi, Muna, West Muna, East Kolaka and Bau-Bau City areas. The highest increase in cases occurred in Wakatobi District with topping The increase occurred in 2023. Analysis of the best trend model for predicting the number of malnutrition cases in Southeast Sulawesi Province in 2019-2023 is quadratic.
\end{abstract}

Keywords: malnutrition; forecasting; timeseries 


\section{PENDAHULUAN}

Masalah gizi buruk pada balita merupakan masalah kesehatan masyarakat sejak dahulu. Gizi buruk adalah bentuk terparah dari proses terjadinya kekurangan gizi menahun.Anak Balita rentan untuk menjadi gizi buruk karenadalam masa tumbuh kembang $^{1}$.Situasi global berdasarkan data World Health Organisation (WHO) pada tahun 2017 menunjukkan bahwa jumlah kematian anak di bawah usia 5 tahun mencapai 5,9 juta diseluruh dunia. Faktor yang berhubungan dengan giziberkontribusi sekitar $45 \%$ dari kematian pada anak di bawah usia 5 tahun ${ }^{2}$. Secara nasional, prevalensi gizi buruk di Indonesia pada tahun 2016 sebesar 3,40\% dan meningkat menjadi 3,80\% pada tahun 2017. Dari 34 provinsi di Indonesia pada tahun 2017, Provinsi Sulawesi Tenggara menduduki urutan ke 4 dengan prevalensi gizi buruk sebesar 6,50\% yang meningkat dari tahun 2016 sebesar 2,05\%. Dengan demikian, kasus gizi buruk merupakan salah satu masalah kesehatan yang perlu perhatian khusus dalammelakukan penanggulangan ${ }^{3}$.

Profil Dinas Kesehatan Provinsi Sulawesi Tenggara tahun 2017 menunjukkan bahwa secara umum jumlah kasus gizi buruk di Provinsi Sulawesi Tenggara dalam 5 tahun terakhir mengalami penurunan. Jika tahun 2013 ditemukan 333 kasusmaka pada tahun 2017 turun menjadi 220 kasus. Namundibalik penurunan jumlah kasus tersebut, gizi buruk masih menjadi masalah kesehatan yang memprihatinkan. Berdasarkan sebaran kasus gizi buruk pada balita menurut Kabupaten/Kota Provinsi Sulawesi Tenggara tahun 2017, tidak ada wilayah di Sulawesi Tenggara yang bebas dari kasus gizi buruk, bahkan rata-rata berada di atas 10 kasus gizi buruk, dengan Kabupaten Bombana, Muna dan Buton memiliki jumlah kasus tertinggi. Dalam upaya penanganan gizi buruk, program gizi memiliki kriteria bahwa 1 kasus gizi buruk di suatu daerah sudah dapat dikategorikan ke dalam Kejadian Luar Biasa (KLB) gizi buruk. Mengacu pada kriteria ini, maka pada tahun 2017 di seluruh wilayah Sulawesi Tenggara telah mengalami KLB gizi ${ }^{4}$.

Berdasarkan uraian masalah tersebut, perlu diperhatikan dalam melakukan focus arah pengambilan kebijakan pencegahan dan penanggulangan gizi buruk sejak dini. Salah satu upaya yang dapat dilakukan untuk pencegahan dini adalah dengan analisis peramalan (forecasting) data berkala (time series). Analisis forecasting dengan metode time series dapat membantu memberikan informasi awal sebagai bahan pertimbangan dalam pengambilan keputusan. Penelitian mengenai forecasting banyak dilakukan dalam bidang ilmu perekonomian dan matematika. Akan tetapi, seiring berjalannya waktu, metode forecasting mulai digunakan dalam penelitian kesehatan. Beberapa penelitian terdahulu mengenai peramalan cukup efektif dalam melakukan peramalan. Hasil penelitian menggunakan metode analisis trend waktu dalam ketidaksetaraan sosial-ekonomi dalam prevalensi pendek yang merupakan analisis survei nasional berulang ${ }^{5}$. Selainitu, hasil penelitian yang meramalkan trend analisis dengan metode time series untuk meramalkan penderita tuberkulosis (TB) tahun 2017-2021 berdasarkan data penderita TB tahun 2012-2016 .

\section{METODE}

Penelitian ini menggunakan metode penelitian kuantitatif deskriptif dengan pendekatan Analisis Data Sekunder (ADS) yang dianalisis dengan analisis rangkaian berkala (time series). Penelitian dilaksanakan bulan Mei - Juli 2019.Populasi yang digunakan dalam penelitian ini adalah seluruh data time series (data deretan waktu) gizi buruk berdasarkan wilayah kabupaten/kota selama periode 2015- 2017 di Provinsi Sulawesi Tenggara sebanyak 744 data.

Sampel adalah anggota populasi yang dianggap dapat mewakili populasi. Besarnya sampelharus mencerminkan karakteristik populasi agar data yang diperoleh representatif (terwakili). Agar dapat menggambarkan secara tepat variabel yang diteliti, maka peneliti mengambil semua populasi sebagai sampelnya. Oleh karena itu, pengambilan sampel dalam penelitian ini menggunakan metode sampling jenuh.Metode sampling jenuh atau istilah lainnya sensus merupakan teknik penentuan sampel bila semua anggota populasi digunakan sebagai sampel ${ }^{7}$.Berdasarkan teknik pengambilan sampel tersebut, diperoleh jumlah sampel (n) daridata time seriessetiap tahun selama periode 2015 - 2017.

Variabel penelitian dalam penelitian initerdiri dari variabel dependen dan independen.Variabel dependen adalah kasus gizi buruk sedangkan variabel independen meliputi wilayah kabupaten/kota dan waktu.Sumber data dalam penelitian ini berasal dari data sekunder yang diperoleh dari data gizi buruk berdasarkan jenis kelamin dan wilayah kabupaten/kota, yang diambil dari Dinas KesehatanProvinsi Sulawesi Tenggara periode selama periode 2015 - 2017.

Pengolahan data dalam penelitian ini menggunakan program Microsoft Excel sedangkan 
analisis data menggunakan analisis time series dengan pendekatan metode trend (trend linier, trend quadratic dan trend exponensial). Setelah data dianalasis kedalam 3(tiga) model tersebut, selanjutnya kita akan melihat nilai R. square (koefesien determinasi), MAE (nilai rata-rata kesalahan prediksi) dan MAPE (nilai persentase kesalahan prediksi) yang didapatkan. Semakin besar nilai R. Square yang didapatkan, maka semakin bagus model trend tersebut untuk memprediksi suatu kejadian,dan semakin kecil hasil perkalian dari nilai MAE dan MAPE, maka semakin akurat model tersebut untuk memprediksi suatu kejadian ${ }^{8}$.

\section{HASIL DAN PEMBAHASAN}

Tabel 1. Distribusi jumlah kasus gizi buruk tahun 2015 -

\begin{tabular}{lccc} 
& 2017 & & \\
\hline \multicolumn{1}{c}{ Kabupaten } & 2015 & 2016 & 2017 \\
\hline Buton & 28 & 32 & 25 \\
Muna & 45 & 31 & 26 \\
Konawe & 14 & 23 & 11 \\
Kolaka & 15 & 9 & 4 \\
Konawe Selatan & 23 & 31 & 17 \\
Bombana & 31 & 35 & 34 \\
Wakatobi & 5 & 8 & 23 \\
Kolaka Utara & 14 & 26 & 18 \\
Buton Utara & 4 & 3 & 1 \\
Konawe Utara & 8 & 1 & 10 \\
KolakaTimur & 0 & 2 & 2 \\
KonaweKepulauan & 3 & 2 & 3 \\
Muna Barat & 4 & 7 & 4 \\
Buton Tengah & 16 & 26 & 4 \\
Buton Selatan & 17 & 13 & 12 \\
Kota Kendari & 10 & 23 & 16 \\
Kota Bau-Bau & 8 & 7 & 10 \\
\hline
\end{tabular}

Tabel 1 menunjukkan jumlah kasus gizi buruk berdasarkkan wilayah kabupaten/kota tahun 2015 -
2017, dengan jumlah kasus terbanyak berada pada tahun 2015 di Kabupaten Muna sebanyak 45 Kasus.

Gambaran peningkatan kasus pada gambar 1 menunjukkan bahwa dalam tahun 2015 - 2017, kasus gizi buruk di wilayah kabupaten/kota Provinsi Sulawesi Tenggara berfluktuatif. Kasus gizi buruk tertinggi pada tahun 2015 berada di Kabupaten Muna dan terendah di Kolaka Timur, sedangkan kasus gizi buruk tertinggi pada tahun 2016 berada di Kabupaten Bombana dan terendah di Konawe Utara. Dan untuk tahun 2017, kasus tertinggi masih berada di Kabupaten Bombana dan terendah di Buton Utara.

Hasil prediksi jumlah kasus gizi buruk berdasarkkan wilayah kabupaten/kota tahun 2019 2023 menggunakan trend model quadratic menunjukkan bahwa jumlah kasus tertinggi berada pada tahun 2023 di Kabupaten Konawe Utara sebanyak 400 Kasus.

Gambaran peningkatan kasus padagambar 2 menunjukkan bahwa dalam tahun 2019 - 2023, kasus gizi buruk di wilayah kabupaten/kota Provinsi Sulawesi Tenggara terjadi pada wilayah Kabupaten Muna, Bombana, Wakatobi, Konawe Utara, Kolaka Timur, Muna Barat, Buton Selatan dan Kota BauBau. Peningkatan jumlah kasus tertinggi diprediksi akan terjadi pada tahun 2019 sampai 2020 di Kabupaten Wakato bidan tahun 2021 sampai 2023 berada di Kabupaten Konawe Utara, dengan puncak peningkatan terjadi pada tahun 2023. Penurunan kasus tertinggi terjadi di Kabupaten Buton Tengah dengan puncak penurunan berada pada tahun 2023.



Gambar 1. Distribusi kasusgiziburukberdasarkankabupaten/kotadi Provinsi Sulawesi Tenggara berdasarkankabupaten/kotatahun 2015 - 2017 

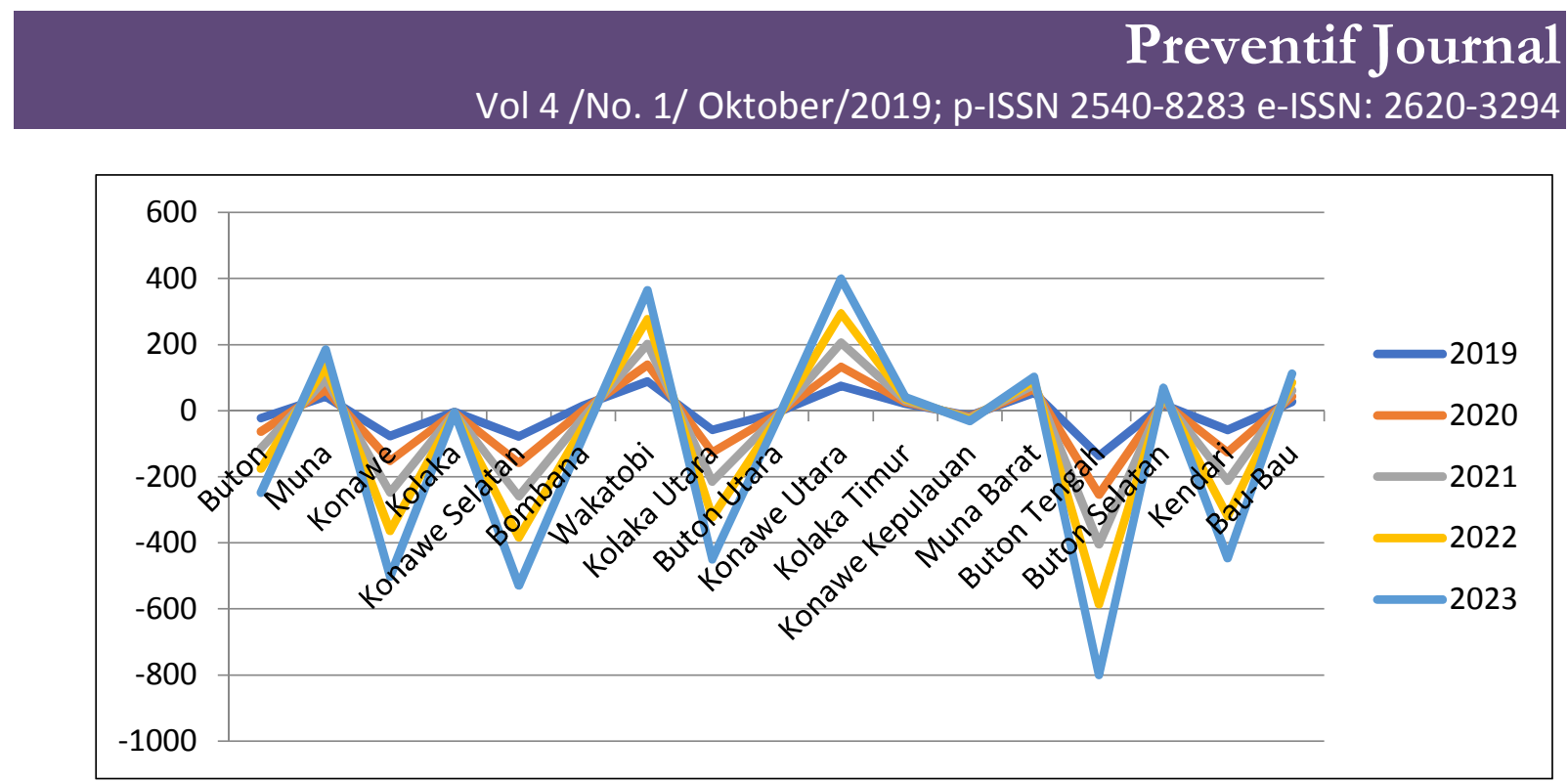

Gambar 2.Trend model quadratic kasusgiziburuk di Provinsi Sulawesi Tenggara BerdasarkanKabupaten/Kota tahun 2019-2023

Gizi buruk menjadi masalah kesehatan yang memprihatinkan, tidak hanya di tingkat internasional namun juga di tingkat nasional. Berdasarkan data hasilPemantauan Status Gizi (PSG)tahun 2017 menunjukkan bahwa data gizi buruk berada di seluruh wilayah provinsi di Indonesia salah satunya adalah Provinsi Sulawesi Tenggara ${ }^{9}$. Jumlah penderita gizi buruk di Provinsi Sulawesi Tenggara tidak terlepas dari sumbangan angkakejadiangiziburuk yang diberikan oleh kabupaten/kota yang berada didalamnya.

Hasil prediksi jumlah kasus gizi buruk tahun 2019 - 2023 menggunakan model quadratic. Hal ini dikarenakan nilai $\mathrm{R}$ square pada trend model quadratic memiliki nilai yang paling besar. Semakin besar nilai R. square yang didapatkan, maka semakin bagus model trend tersebut untuk memprediksi suatu kejadian, dan semakin kecil hasil perkalian dari nilai MAE dan MAPE, maka semakin akurat model tersebut untuk memprediksi suatu kejadian ${ }^{10}$.

Berdasarkan hasil prediksi kasus gizi buruk di Provinsi Sulawesi Tenggara tahun 2019 - 2023 diperoleh beberapa wilayah kabupaten/kota dengan kasus yang meningkat yakni Kabupaten Muna, Wakatobi, Konawe Utara, Muna Barat, Buton Selatan, Kolaka Timur dan Kota Bau-Bau. Penurunan kasus akan terjadi di Kabupaten Kolaka, Konawe Kepulauan, Buton Utara, Bombana, Buton, Kolaka Utara, Konawe, Konawe Selatan, Buton Tengah dan Kota Kendari. Hal inididuga terjadikarena faktor geografis dan degmografi. Dikatakanbahwakarakteristik yang berbeda seperti distribusi geografis berdasarkan indikator gizi buruk antar wilayahakan menyebabkan kualitas kesehatan yang berbeda pula pada tiap wilayahnya ${ }^{11}$.
Kondisi topografi tanah di daerah Provinsi Sulawesi Tenggara umumnya memiliki permukaan yang bergunung-gunung, bergelombang dan berbukit-bukit. Diantara gunung dan bukit-bukit, terhampar dataran-dataran yang merupakan daerah pertanian dan perkebunan yang subur. Sebagian besar penduduk Provinsi Sulawesi Tenggara bermukim di sepanjang wilayah pesisir dengan mata pencaharian utama sebagai nelayan dan sebagian yang lain di daerah pedalaman dan bekerja sebagai petani. Fakta ini membuat Sulawesi Tenggara memiliki keragaman budaya dan adat istiadat dengan karakteristik yang berbeda satu dengan yang lain berdasarkan letak geografis, adanya keragaman dalam berbagai aspek tersebut juga mempengaruhi perilaku masyarakat terhadap kesehatan ${ }^{12}$.

Jumlah dan distribusi penduduk dalam suatu wilayah kabupaten/kota juga akan menentukan jumlah penderita. Jumlah dan distribusi penduduk menentukan kepadatan penduduk di suatu wilayah. Kepadatan penduduk selain menentukan cepat lambatnya penyakit dapat menular, banyak tidaknya penderita apabila terjadi perubahan mendadak seperti kejadian luar biasa dan besar kecilnya tempat pelayanan kesehatan yang memadai. Wilayah yang kepadatan penduduknya tinggicenderung memiliki tempat tinggal yang kumuh, hygiene, gizi yang buruk menyebabkan banyaknya keluarga miskin. Peningkatan keluarga miskin akan menyebabkan pemenuhan gizi menjadi sulit terjangkau sehingga berdampak pada kekurangan gizi. Kekurangan gizi akan menyebabkan daya tahan tubuh menjadi lebih rentan sehingga mudah terpapar oleh agenpenyakit ${ }^{13}$. Selain itu, status giziburuk dihasilkan dari banyak penyebab seperti 
ketersediaan makanan yang terbatas, asupan gizi yang buruk, nafsu makan yang menurun, malabsorpsi dan gangguan metabolisme serta penyakit infeksi karena masah lingkungan di setiap wilayah yang berbeda ${ }^{14}$.

\section{SIMPULAN DAN SARAN}

Simpulan dari penelitian ini adalah analisis trend model terbaik untuk prediksi jumlah kasus gizi buruk di Provinsi Sulawesi Tenggara tahun 2019-2023 adalah quadraticdan hasil analisis trend model quadratic jumlah kasus gizi buruk berdasarkkan kabupaten/kota tahun 2019 - 2023 menunjukkan bahwa peningkatan kasus tertinggi terjadi di Kabupaten Konawe Utara dengan puncak peningkatan terjadi pada tahun 2023.

Saran kepada Dinas Kesehatan Provinsi Sulawesi Tenggara adalah agar dapat meningkatkan upaya pencegahan sejak dini tentang masalah gizi buruk khususnya pada wilayah dengan kasus tertinggi. Kepada peneliti selanjutnya untuk melakukan penelitian dengan skala kecil dan karakteristik yang lebih detil.

\section{DAFTAR PUSTAKA}

1. Supariasa, I., Bakri, B.\&Fajar, I. (2016). Penilaian status gizi edisi 2. Jakarta: EGC.

2. Unicef, WHO \&World Bank Group. (2017). Levels and trends in child malnutrition. USA: UNICEF, WHO \& World Bank Group.

3. Kementerian Kesehatan RI. (2017). Data dan informasi profil kesehatan Indonesia tahun 2016. Jakarta: Pusdatin Kemenkes RI.

4. Dinas Kesehatan Provinsi Sulawesi Tenggara. (2017). Profil kesehatan Provinsi Sulawesi Tenggara tahun 2017. Kendari: Dinas Kesehatan Provinsi Sulawesi Tenggara.

5. Restrepo-Méndez, M.C., Barros, A.J., Black, R.E. \& Victora, C.G. (2015). Time trends in socioeconomic inequalities in stunting prevalence: analyses of repeated national surveys. Public Health Nutrition. 18(12):2097-104.

6. Lubis, L.A. (2018). Trendanalisis dengan metode time series untuk meramalkan penderita tuberkulosis (TB) tahun 2017-2021 berdasarkan data penderita TB tahun 2012-2016 di Kabupaten Mandailing Natal.

7. Sugiyono, H. (2016). Metode kualitatif dan kuantitatif. Cetakan ke-23. Bandung: Alfabeta.

8. Baroroh, A. (2013). Analisis Multivariat dan time series dengan SPSS 21. Jakarta: Elex Media Komputindo.

9. Kementerian Kesehatan RI. (2017). Hasil pemantauan status gizi (PSG) tahun 2016.
Jakarta: Direktorat Bina Gizi Masyarakat, Dirjen Kesehatan Masyarakat.

10. Juanda, B. \& Junaidi, J. (2012). Ekonometrika deret waktu: teori dan aplikasi. Bogor: IPB Press.

11. Fadmi, F.R. Prediksi jumlah kasus baru kusta dengan metode Geographically Weighted Poisson Regression (GWPR).

12. Fadmi, F.R., Mulyani, S. \& Buton, L.D. (2018). Geographically Weighted Regression (GWR) approach in the modeling of malnutrition and the influencing factors in Muna Regency. Indian Journal of Public Health Research \& Development. 9(6).

13. Bhandari, T.R. (2012). Maternal and child health situation in South East Asia. Nepal Journal of Obstetrics and Gynaecology. 7(1):510.

14. Hove-Musekwa, S.D., Nyabadza, F., Chiyaka, C., Das, P., Tripathi, A. \& Mukandavire, Z.. (2011). Modelling and analysis of the effects of malnutrition in the spread of cholera. mathematical and computer modelling. 53(910):1583-95. 